\title{
Arid/humid patterns over Asia in response to national-committed emission reductions under the Paris agreement
}

\author{
Fang Wang ${ }^{1 * \dagger}$ (D) and Jintao Zhang ${ }^{1,2+}$
}

\begin{abstract}
The evolution of regional arid/humid patterns caused by global climate change deserves attention. We investigated the changes in the area of arid/humid climate regions over Asia under the aegis of national-committed emission reductions to comply with the Paris Agreement using an ensemble of 17 global climate models (GCMs) from the Fifth Coupled Climate Model Intercomparison Project (CMIP5) archives. Our results indicated an overall trend towards aridity in a future warmer climate based on an aridity index (Al), defined as the ratio of precipitation to potential evapotranspiration (PET). In the future, the humid region will contract and the arid region and arid/humid transition zones will expand. Compared with the present period, arid/humid region switch is projected to occur in a land area of $2512.8 \times 10^{3} \mathrm{~km}^{2}$ over Asia under the Intended Nationally Determined Contributions (INDC)-pledge scenario. If global warming is controlled to the ambitious $2.0^{\circ} \mathrm{C}$ and $1.5^{\circ} \mathrm{C}$ scenarios instead of that of the INDCpledge scenario, a decrease in the changes in the area of arid/humid regions by more than half would be expected. In addition, the arid/humid regions with continuous global warming are estimated to contract/expand greatly. Changes in the spatial pattern of the arid/humid zones over Asia show strong similarities between multimodel simulations, although there are some differences in detail.
\end{abstract}

Keywords: Arid/humid patterns, Aridity index, Climate change, Asia, INDC

\section{Introduction}

According to the Fifth Assessment Report of the Intergovernmental Panel on Climate Change (IPCC), the global mean temperature increased $0.85^{\circ} \mathrm{C}\left(0.65-1.06^{\circ} \mathrm{C}\right)$ between 1880 and 2012, and a larger increase is projected in the future (IPCC 2014). Changes in regional aridity are among the primary effects anticipated under global warming (Dai 2012, Trenberth et al. 2013, Greve and Seneviratne 2015). Changes in moisture conditions greatly affect the distribution of arid/humid patterns (Yin et al. 2015), but accurately quantifying those effects remains a challenge. Projected changes in temperature and precipitation will cause shifts in arid/humid climate zones worldwide (Hanf et al. 2012, Feng et al. 2014,

\footnotetext{
* Correspondence: wangf@igsnrr.ac.cn

${ }^{\dagger}$ Fang Wang and Jintao Zhang are the co-first authors, and they contributed equally to this work.

${ }^{1}$ Key Laboratory of Land Surface Pattern and Simulation, Institute of Geographic Sciences and Natural Resources Research, Chinese Academy of Sciences, Beijing 100101, China

Full list of author information is available at the end of the article
}

Rohli et al. 2015). Present-day climate types will gradually shift towards warmer and drier types over the twenty-first century according to the Representative Concentration Pathway 8.5 (RCP8.5) scenario (Feng et al. 2014). The projected expansion of arid regions, semi-arid regions, or both has been investigated in West Africa (Sylla et al. 2016), the Mediterranean (Gao and Giorgi 2008, Alessandri et al. 2014), and China (Li and Ma 2013, Ma et al. 2019). However, to what extent future climate change will affect arid/humid regions in Asia is unknown and differs among regions.

The Paris Agreement sets a limit of $2{ }^{\circ} \mathrm{C}$ on the global mean temperature change and pursues efforts to limit warming to $1.5^{\circ} \mathrm{C}$ relative to preindustrial levels (UNFCCC 2015a, b). To achieve the goal of the Paris Agreement, countries submitted national mitigation plans in the form of Intended Nationally Determined Contributions (INDC) (UNFCCC 2019). Most past studies projected changes in the climate at a specific time in the future on the basis of a series of greenhouse gas and 
aerosol forcing scenarios, such as RCPs (van Vuuren et al. 2011). In contrast, the focus of the Paris Agreement and current mitigation commitments negotiated by governments is on global mean warming limits. Therefore, it is more important to quantify projected climate changes using the temperature targets associated with the current mitigation commitments negotiated by governments rather than prearranged emission scenarios.

In our study, we examined the trend in hydroclimatic variables using the INDC emission reduction scenarios for the next few decades and investigated the changes in arid/ humid regions using observational climatology and an ensemble of comprehensive global climate models (GCMs) from the Fifth Coupled Climate Model Intercomparison Project (CMIP5). Specifically, potential evapotranspiration was estimated using the revised Penman-Monteith model and was then combined with precipitation to construct an aridity index to classify arid/humid climate types. Our results revealed the sensitivity of arid/humid patterns to projected climate change and indicated the hotspot regions, providing a scientific foundation for making policy with respect to climate change.

\section{Data and methods}

\section{Emission scenarios}

In this study, the INDC mitigation target scenarios based on the Paris Agreement were analysed. We calculated future quantified emission targets for each country using the normalisation method and INDC emissions data submitted by 192 countries (UNFCCC 2019). Because the published INDCs provide emission targets proposed to be achieved by 2030, we extended the INDC scenarios to the end of this century by analysing the IPCC AR5 scenario database. Detailed information is provided in Text S1. We focused on the INDC-sustained mitigation scenario (hereafter, INDC pledge; Fig. S1), which is consistent with the 'continued action' pathway reported in Rogelj et al. (2016), Wang et al. (2018), and CAT (2017). We further estimated the global mean warming (at the end of this century) response to the INDC-sustained mitigation and determined that $\Delta T_{\mathrm{INDC}} \approx 2.9-3.3^{\circ} \mathrm{C}$ (median $\left.=3.1^{\circ} \mathrm{C}\right)$ is the most likely temperature increase range for the 'continued action' pathways of the INDCs (Zhang and Wang 2019) (Text S2).

In addition, we analysed the $2.0^{\circ} \mathrm{C}$ and $1.5^{\circ} \mathrm{C}$ temperature target scenarios consistent with the Paris Agreement. The $2.0^{\circ} \mathrm{C}$ and $1.5^{\circ} \mathrm{C}$ target scenarios are based on the AR5 (IPCC 2014) and $1.5^{\circ} \mathrm{C}$ Special Report of the IPCC (IPCC 2018).

\section{Data description}

To derive the regional climate changes and the corresponding spatial shifts in the arid/humid zones across Asia, we adopted 17 state-of-the-art CMIP5 GCMs
(Taylor, Stouffer, and Meehl 2011). Basic information about these GCMs is summarized in Table S1. The predictions by the mean of the ensemble of these GCMs are better than that of any individual ensemble member because the uncertainty of the predictions corresponds to the intermodel variability, which can be filtered (Reichler and Kim 2008, Pierce et al. 2009). Therefore, the multimodel ensemble mean was used to reflect the future climatic characteristics. All model data were interpolated to a common $0.5 \times 0.5$ horizontal grid for ensemble analyses, and, to treat all models equally, we selected the first run for the multiple-ensemble models.

The CRU (Climate Research Unit) Time Series dataset v. 4.03 , with a horizontal resolution of $0.5 \times 0.5$ based on stationary observation (Harris et al. 2014), was used to validate the GCMs. Before simulation data are used to study the impact of climate change, a linear correction using the bias correction method is recommended to reduce the bias of climate model simulations compared with observed climate data (Durman et al. 2001) (Text S3). Here, the simulated climatic variables were adjusted to have the same climatological annual mean as the real observations over Asia for the baseline period 19611990. While the general features of the observed arid/ humid patterns were reasonably reproduced by the corrected model data, mild biases were evident (Figs. S3 and S4).

With respect to the social impact, the projected population distributions under different shared socioeconomic pathways (SSPs) (Jones and O'Neill 2016) were used to investigate the population distribution in changing arid/humid climate regions. In this paper, we present the population-related results estimated using the population projected for 2100 under the SSP2 scenario because the results based on projections under other SSP scenarios are qualitatively similar.

Since the internal variability can lead to uncertainty of climate change projection (Hu et al., 2019), on the basis of previous research (Robert et al. 2014, Schleussner et al. 2016, Huang et al. 2017), we used a time slice approach in which the spatial state at a specific warming point with respect to $\Delta T_{\mathrm{INDC}}$ (or $2.0^{\circ} \mathrm{C}, 1.5^{\circ} \mathrm{C}$ ) is taken from decadal time slices, with the respective mean warming for each model taken separately. More generally, this time slice approach can relate various climate indicators to global mean warming (see Text S4).

\section{Arid/humid zone classification}

The interplay between water supply and demand, including both precipitation $(P)$ and potential evapotranspiration (PET), is critical to the projection of changes in dryness (Cook et al. 2014, Greve and Seneviratne 2015, McEvoy et al. 2016) and dryland dynamics (Huang et al. 2017). The aridity index (AI), expressed as the ratio of $P$ 

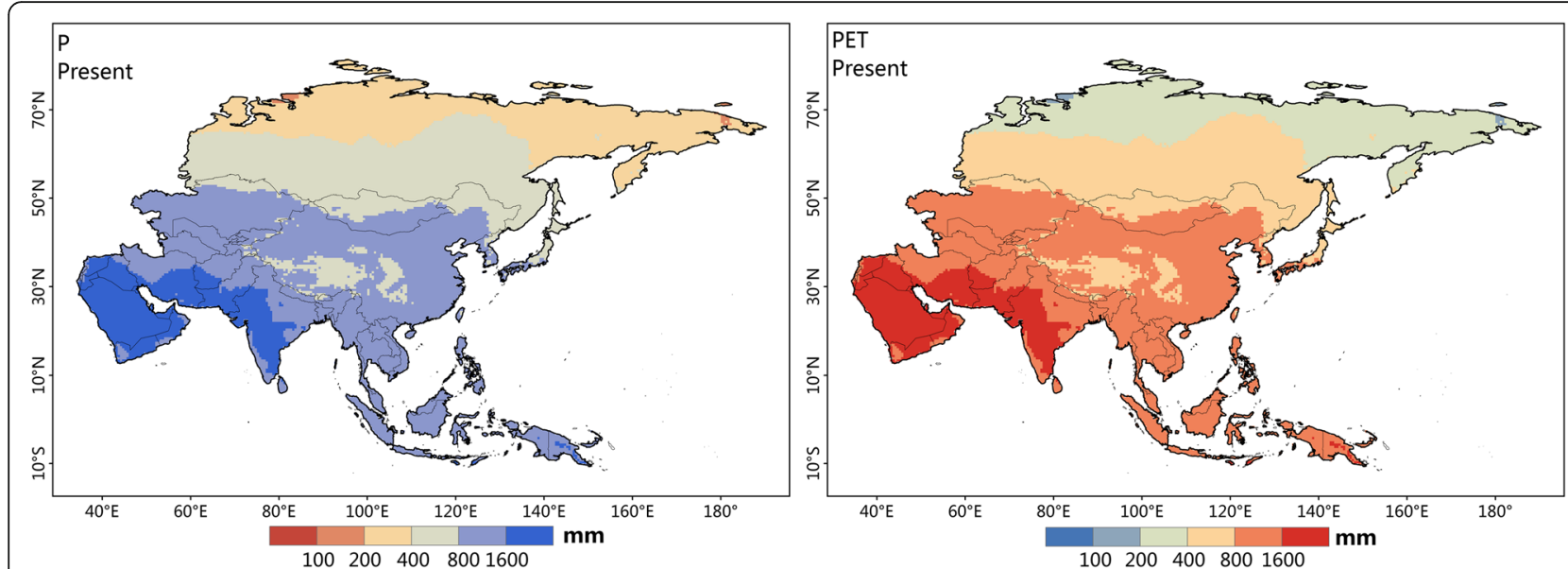

Fig. 1 Annual precipitation and PET across Asia for the present period. Annual precipitation (left) and PET (right) across Asia for the present period (1985-2005) based on CRU observational data

to PET (Budyko 1974), is widely used as an indicator of regional moisture conditions and is an effective index for classifying arid/humid zones. In general, PET indicates the maximum water demand for an environment to maintain its water balance, and $P$ reflects the water supply over large scales. Because PET observed over large regions is difficult to determine, we considered the Penman-Monteith model (Text S5), a widely used method to simulate PET (Allen and Ingram 2002). It is used to project long-term drought and dryland evolution under climate change (Sherwood and Fu 2014, Huang et al. 2017). Present-day P, PET, and AI based on the above methods are displayed in Figs. 1 and 2.

Currently, more researchers have generally divided the climate classification of drylands using the AI criteria and considered that the PET estimated by the common
Penman-Monteith equation is closer to the real-world conditions under all climates (e.g. Fu and Feng, 2014; Yang et al., 2017). Based on the United Nations Convention to Combat Desertification classification, drylands are characterised by $P / \mathrm{PET}<0.65$ and are further divided into hyperarid $(P / \mathrm{PET}<0.05)$, arid $(0.05<P / \mathrm{PET}<0.2)$, semiarid $(0.2<P /$ PET $<0.5)$, and dry sub-humid $(0.5<P /$ PET $<0.65)$ regions (Middleton and Thomas, 1997). In this paper, we broadly classify the land surface into four zones based on AI (AI=P/PET): humid, sub-humid, semiarid, and arid, with details given in Table 1.

\section{Results}

Changes in P and PET

Changes in multi-model-projected $P$ and PET under $1.5^{\circ} \mathrm{C}, 2.0^{\circ} \mathrm{C}$, and INDC-pledge scenarios relative to the

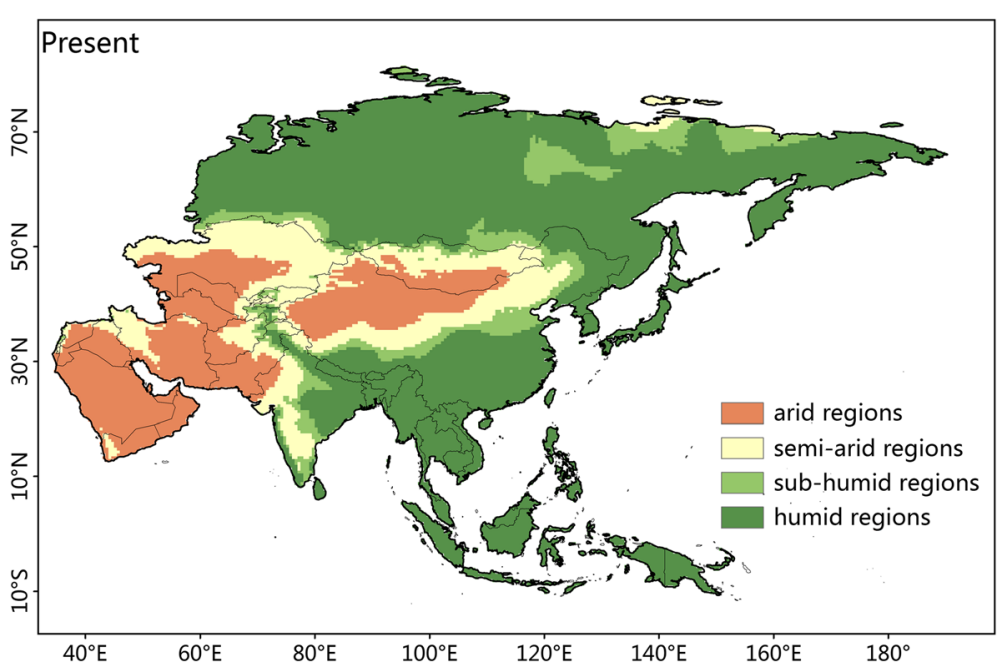

Fig. 2 Arid/humid climate regions across Asia for the present period. Arid/humid climate regions across Asia for the present period (1985-2005) based on CRU observation data 
Table 1 Criteria for demarcating the arid/humid climate regions of Asia according to Al

\begin{tabular}{ll}
\hline Arid/humid climate region & Aridity index $(\mathrm{Al}=\mathrm{P} / \mathrm{PET})$ \\
\hline Humid & $\mathrm{Al} \geq 0.65$ \\
Sub-humid & $0.5 \leq \mathrm{Al}<0.65$ \\
Semi-arid & $0.2 \leq \mathrm{Al}<0.5$ \\
Arid & $\mathrm{Al}<0.2$ \\
\hline
\end{tabular}

present day are shown in Fig. 3. Annual precipitation increases moderately $(<10 \%)$ over most of Asia under the INDC-pledge scenario, with the most prominent increase (up to $30 \%$ or more) in the northern periphery of the Tibetan Plateau. By contrast, a decrease is seen in some regions in the Middle East, Central Asia, and southern China. There are less significant changes in the annual $\mathrm{P}$ under the $1.5^{\circ} \mathrm{C}$ and $2.0^{\circ} \mathrm{C}$ scenarios, although the spatial distribution of variation is similar. The projected increasing precipitation across Asia can be mostly explained by the thermodynamical mechanism, which assumes fixed atmospheric flow patterns but increased water vapour in the lower troposphere (Held and Soden, 2006). However, the changes in atmospheric circulation partially oppose this thermodynamic response in some regions (Allan, 2012).

On the other hand, annual PET (simulated using the Penman-Monteith model) is likely to significantly increase across almost the entire continent under the INDC-pledge scenario, with a relatively uniform increase of $0-20 \%$ in most lands. In general, the larger relative increases occur at the high latitudes. The changes in PET under the $1.5^{\circ} \mathrm{C}$ and $2.0^{\circ} \mathrm{C}$ scenarios also show a spatial pattern similar to but smaller than the results under the INDC-pledge scenario. The overall change of the annual PET is more significant than that in the annual $\mathrm{P}$ based on the results of statistical tests (stippling in Fig. 3). The significant increase in PET can be mainly explained by a thermodynamical mechanism that the warming is causing a higher vapour pressure deficit and evaporative demand. PET is also affected by other factors such as net radiation, wind, and humidity (Huang et al., 2017, 2019).

Future changes in the arid/humid pattern are determined by the combination of changes in $P$ and PET. The increase in PET is more remarkable than that in $P$ (columns 1 and 2 in Fig. 3), resulting the degree of aridity increases over most regions in Asia in the future
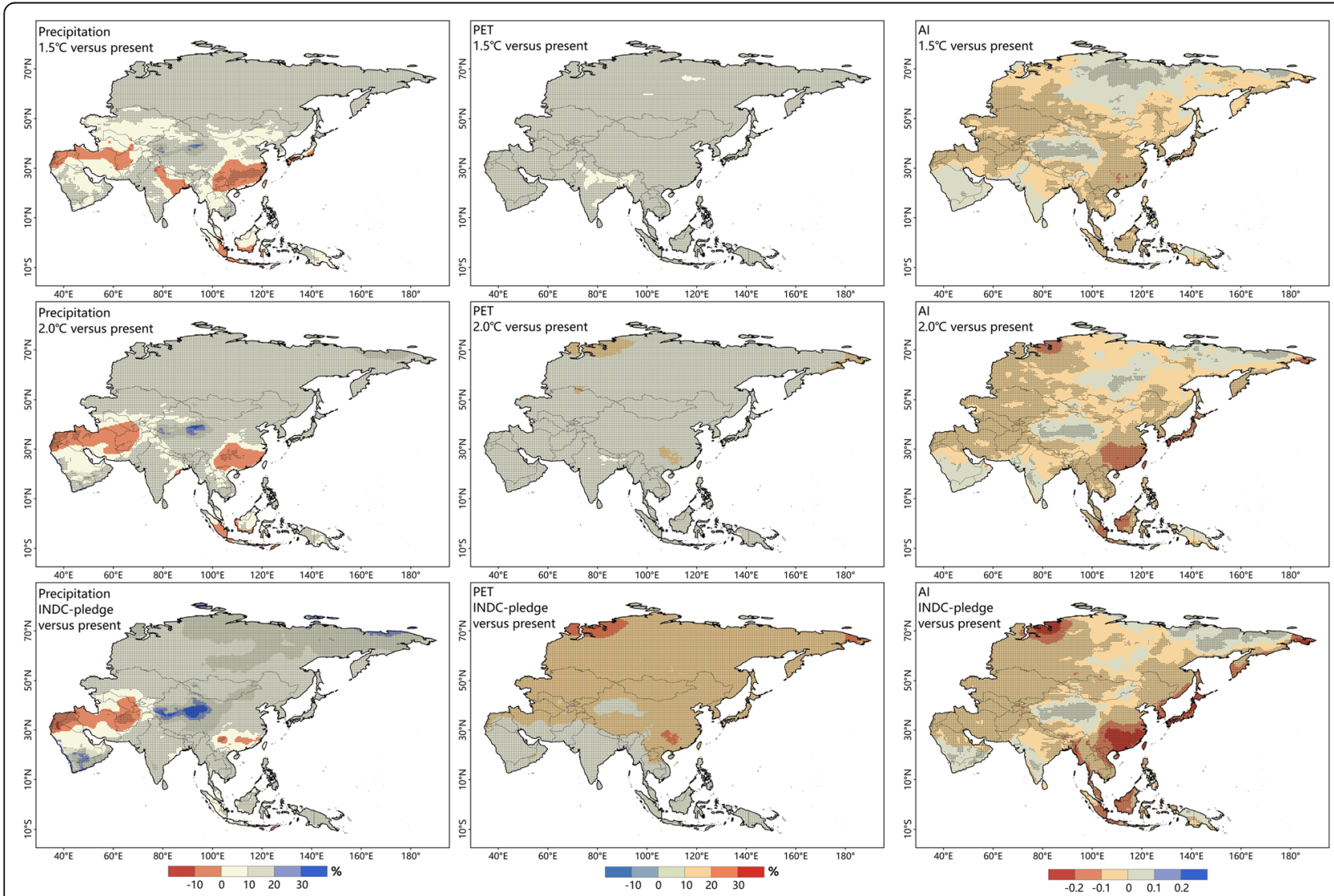

Fig. 3 Changes in annual precipitation, PET, and Al across Asia. Changes in annual precipitation (left column), PET (middle column), and Al (right column) across Asia (multi-model mean). The scenario used is indicated in the upper-left corner of each panel. Black stippling indicates areas where at least $2 / 3$ models agree on the sign of the changes for each grid 

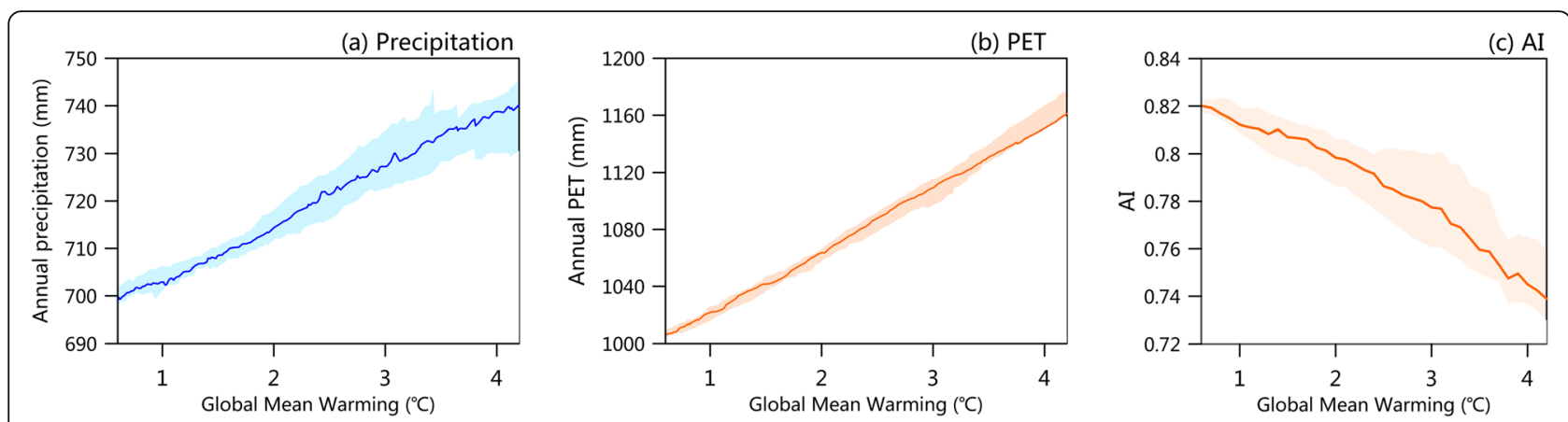

Fig. 4 Asian mean annual precipitation, PET, and Al as a function of warming level. The solid line is the multi-model mean, and the shaded area is the interquartile range

(column 3 in Fig. 3). The average AI in Asia has a decreasing trend with continuous global warming and an overall trend towards aridity (Fig. 4). The areas with remarkable decreases in the AI include southern China, Japan, and northwest Russia, while the $\mathrm{AI}$ over the $\mathrm{Ti}$ betan Plateau increases significantly. The changes in the value of the AI do not fully represent the degree of change in arid/humid conditions (e.g. the $\mathrm{AI}$ in arid areas is already very small, so the change in the AI is also small compared with that of humid areas).

\section{Changes in arid/humid regions over Asia}

We estimated the changes in the area of arid/humid climate zones under different scenarios using the AI defined in the 'Arid/humid zone classification' section, first classify the arid/humid climate zones based on AI simulated by separate models, and then analysed the multi-model ensemble mean area of arid/humid zones. We found that the humid regions decreased in size while the arid regions increased in size in future warmer climate. Compared with the present period, arid/humid region switch is projected to occur in a land area of 1427.4 (1279.2 1847.4, range of $25-75 \%$ confidence interval for the multi-model ensemble, and the same confidence interval applies to subsequent values $) \times 10^{3}, 1674.6(1490.2 \sim 1956.5) \times 10^{3}$, and $2512.8(2393.0 \sim 2646.2) \times 10^{3} \mathrm{~km}^{2}$ over Asia under the $1.5^{\circ} \mathrm{C}, 2.0^{\circ} \mathrm{C}$, and INDC-pledge scenarios, respectively, based on multi-model ensemble mean. The sizes of the humid regions show an average net decrease of 113.0 $(-39.7 \sim 171.3) \times 10^{3}, \quad 170.3 \quad(-10.7 \sim 356.1) \times 10^{3}$, and $365.5(160.7 \sim 924.9) \times 10^{3} \mathrm{~km}^{2}$ under the three above scenarios, respectively (where at least $71 \%$ of models agree on the sign of change). Similarly, compared with the present period, the sizes of the arid and semi-arid regions show an average net increase of $184.4(86.4 \sim 358.1) \times 10^{3}$ and $45.0(-31.7 \sim 290.3) \times 10^{3} \mathrm{~km}^{2}$ under the INDCpledge scenario, respectively, with greater global warming (where $82 \%$ of models (for arid) and $71 \%$ of models (for semi-arid) agree on the sign of change). However, the sub-humid region shows no significant change under the different scenarios. The relative net changes in the areas of the humid, sub-humid, semi-arid, and arid regions under the INDC-pledge scenario compare with present period are $-1.52 \%(-3.87 \sim-0.68 \%),-0.34 \%(-9.02 \sim$ 9.12\%), $2.45 \%$ (-0.44 4.19\%), and $1.77 \%$ (0.83 3.45\%), respectively, with the most remarkable areal change occurring in the semi-arid regions.

If warming is at a lower level, Asia will benefit from robust reductions in changes in arid/humid regions (Fig. 5). The impact of changes avoided in arid/humid regions by a lower level of global warming (e.g. $2.0^{\circ} \mathrm{C}$ or $1.5^{\circ} \mathrm{C}$ ) compared with the INDC scenario was investigated using the following equation:

$$
\text { Avoid impact }=\frac{C_{\mathrm{INDC}}-C_{\mathrm{k}}}{C_{\mathrm{INDC}}}
$$

where $C$ represents the change in the areas of arid/ humid regions under a specific scenario compared with the areas under present climatology and the subscript $k$

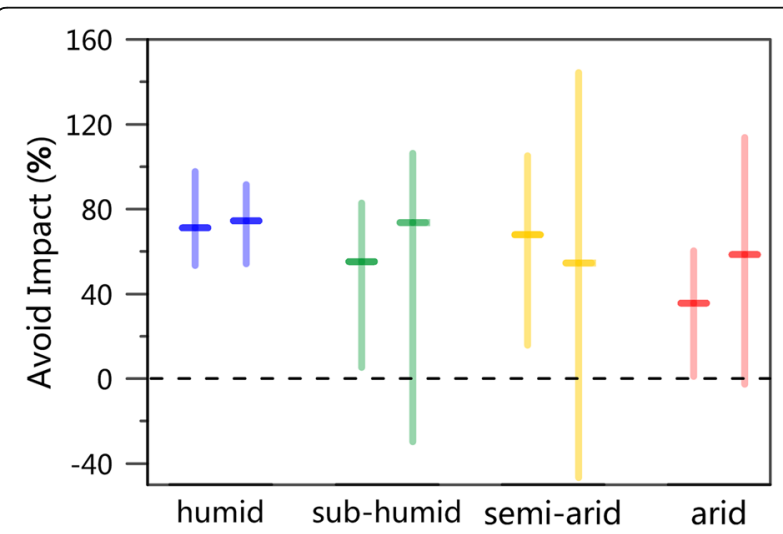

Fig. 5 Changes in the area of arid/humid regions over Asia that are avoided in less warming scenarios. Left bars are the $2.0^{\circ} \mathrm{C}$ scenario compared with the INDC-pledge scenario, and right bars are the $1.5^{\circ} \mathrm{C}$ scenario compared with the INDC-pledge scenario. Horizontal lines denote multimodal median, and the length of the vertical lines denotes the interquartile range 
indicates the different scenarios (i.e. $2.0^{\circ} \mathrm{C}$ and $1.5^{\circ} \mathrm{C}$ ). Our results showed that the lower warming of the $2.0^{\circ} \mathrm{C}$ target scenario instead of the INDC-pledge scenario will help avoid an approximately $36 \%, 68 \%$, and $55 \%$ increase in arid, semi-arid, and sub-humid regions, respectively, and about a $71 \%$ decrease in humid regions. If global warming is further controlled to $1.5^{\circ} \mathrm{C}$, such remarkable benefit of smaller changes in the areas of arid/humid regions would also be seen (Fig. 5).

We further examined the trend in the variation in arid/humid climate zones at different global warming levels (Fig. 6). For the multi-model median, the area of

(a) Areal proportion
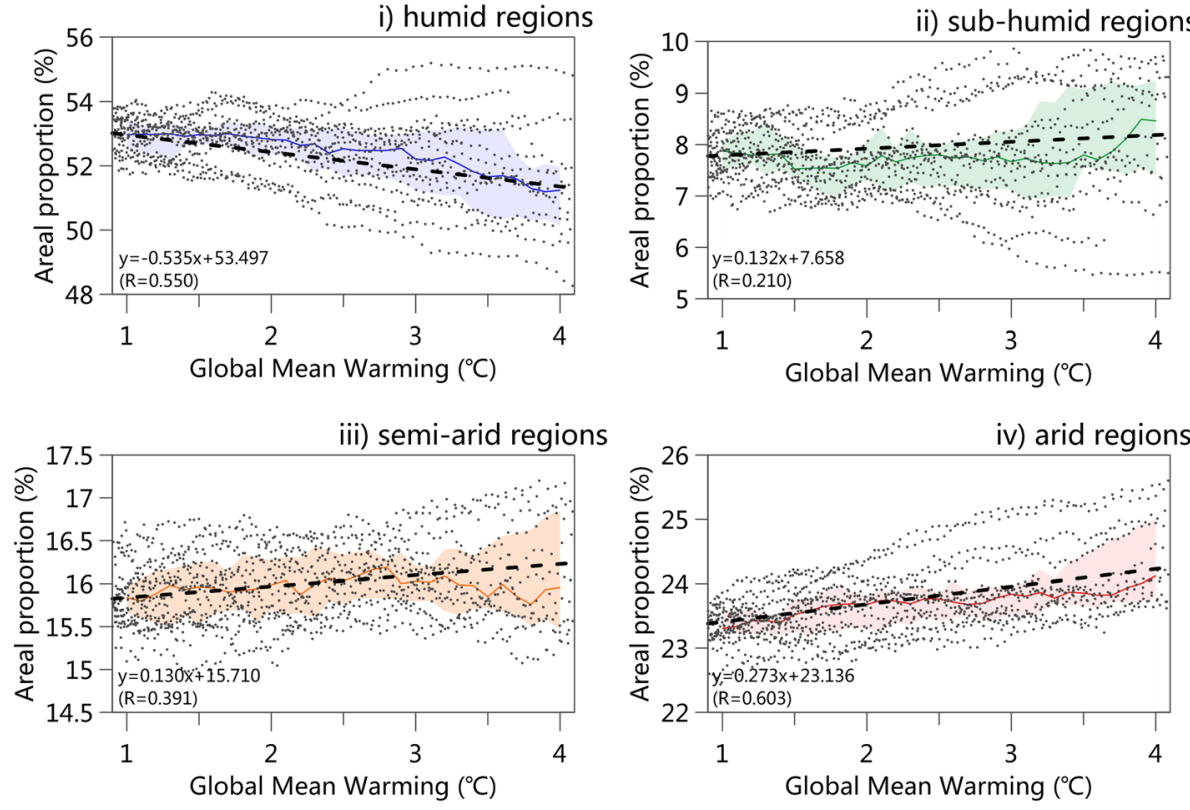

(b) Population proportion
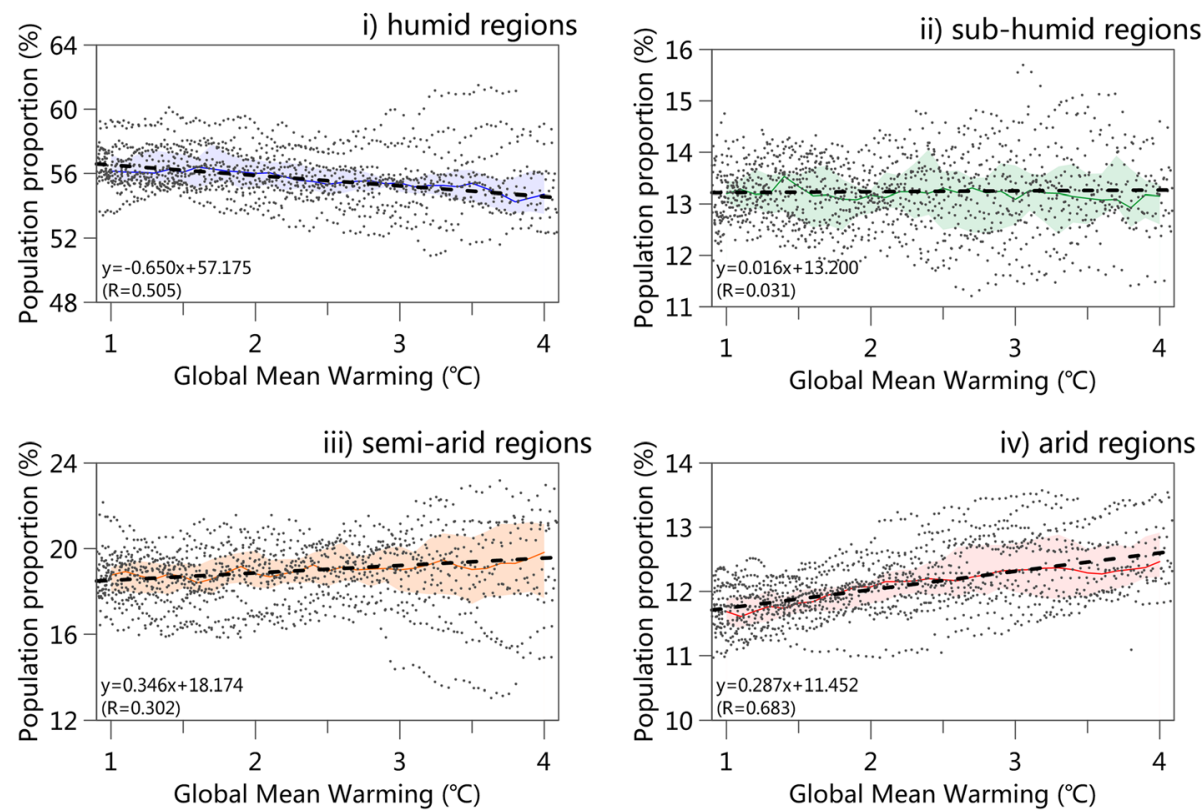

Fig. 6 Areal and population proportion of arid/humid regions as a function of warming level over Asia. Areal proportion (a) and population proportion (b) of humid, sub-humid, semi-arid, and arid regions as a function of warming level over Asia. The dashed lines are the linear trends, while the regression equation and the Pearson's correlation coefficient are labelled on the bottom-left of each subplots. The solid lines and shaded areas indicate multi-model medians and interquartile ranges, respectively. The population proportions at the different warming levels were estimated from the 2100 population projection under the SSP2 scenario 
humid regions was reduced with continuous global warming at a rate of $238.5 \times 10^{3} \mathrm{~km}^{2} /{ }^{\circ} \mathrm{C}$, while the areas of sub-humid, semi-arid, and arid regions increased with global warming at a rate of $58.8 \times 10^{3}, 58.0 \times 10^{3}$, and $121.7 \times 10^{3} \mathrm{~km}^{2} /{ }^{\circ} \mathrm{C}$ per year, respectively. The increase and decrease trends with warming are meaningful only when the associated projection uncertainties remain within reasonable bounds. Inconsistent trends of area of arid/humid regions at higher warming levels are evident mainly attribute to the increasing uncertainties of GCMs itself, and the inconsistent ensemble members (Fig. S2). Compared to the humid and arid regions, the subhumid and semi-arid regions seem to have more significant intermodel variations-with larger variations at high warming levels, which highlight the uncertainties in projected arid/humid pattern between models.

Because regional aridity changes directly affect the amount of water on which human beings depend, we analysed the population distribution in different future arid/humid climate zones. To facilitate comparisons at different global warming levels, the projected population distribution in 2100 under the SSP2 scenario was adopted to estimate the population proportion for the four arid/humid zones at different global warming levels (Fig. 6b). The population tended to be concentrated in the humid (55.6\%) and sub-humid (13.5\%) areas, while a smaller population proportion was in the arid $(18.9 \%)$ and semi-arid (11.9\%) areas (the number in brackets is the present-day level). As global warming intensified, the population proportion in humid regions decreased significantly, dropping to $54.0 \%$ under the INDC pledge, based on the multi-model median. In contrast, the proportion of the population living in arid and semi-arid areas increased with global warming under the INDC pledge to $12.6 \%$ and $19.8 \%$, respectively, whereas the proportion of the population in the sub-humid region showed no significant change under different warming levels.

We took a closer look at the spatial distribution of arid/humid regions over Asia in the warmer future, because the changes (compared with the present period) under the $2.0^{\circ} \mathrm{C}$ and $1.5^{\circ} \mathrm{C}$ scenarios were not as obvious as those under the INDC-pledge scenario; the results for only the INDC-pledge scenario and based on multimodel mean AI are displayed in Fig. 7. Each type of climatic zone has a mild change, mainly on the boundary.
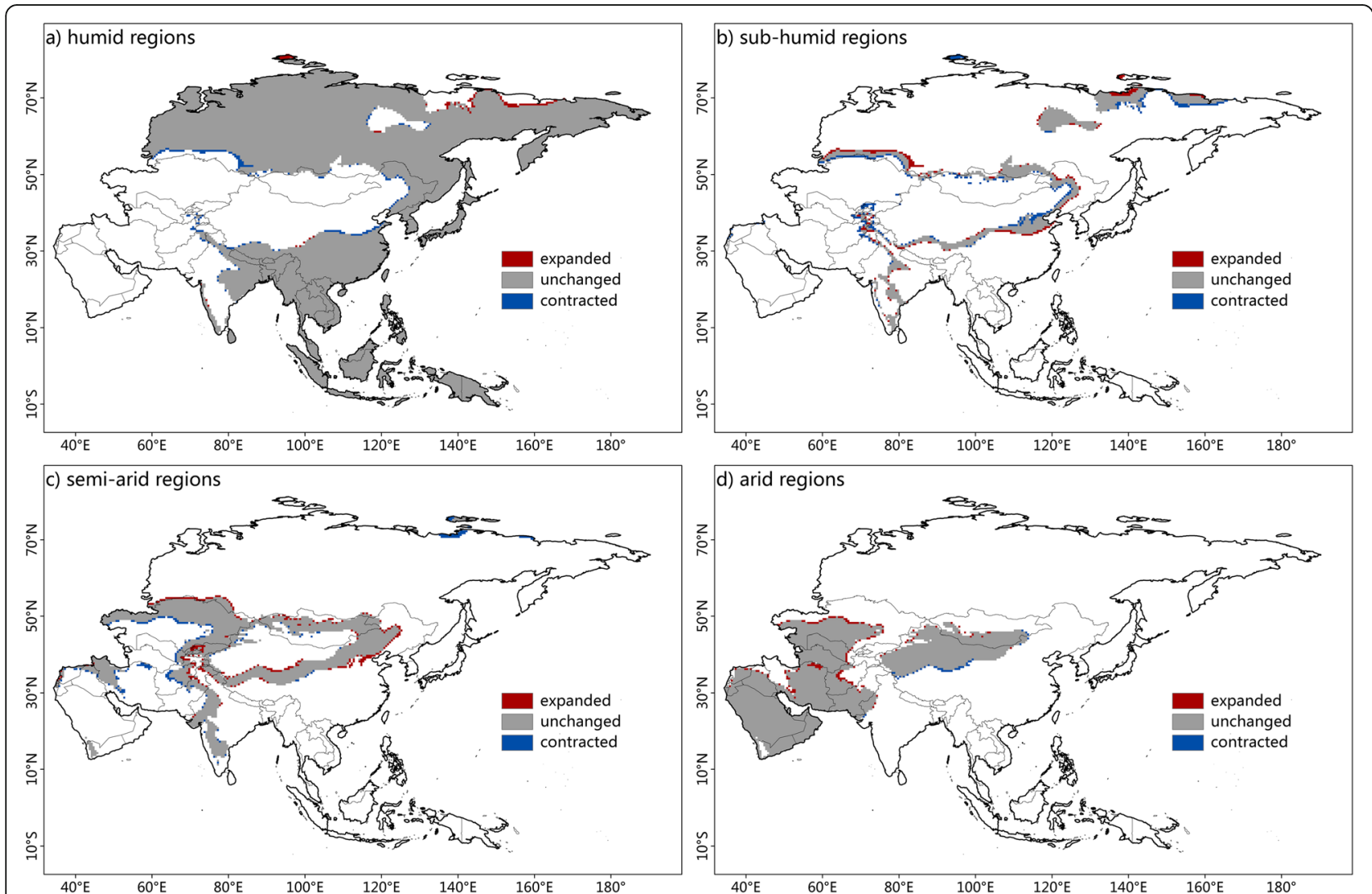

Fig. 7 Spatial distribution of humid (a), sub-humid (b), semi-arid (c), and arid (d) regions over Asia for the INDC-pledge scenario. The different colours indicate changed and unchanged areas relative to the present period. The classification of arid/humid regions are based on multi-model mean Al 
Specifically, the arid regions in West Asia expand to the north and east, while the southern margin of the arid regions in Northwest China contract to the north. The expansion and contraction of semi-arid and sub-humid areas are obvious, but the net effect is an increase in area (as most models show). The expansion of the semiarid zone is most prominent in northern China and the border between Kazakhstan and Russia. There are large differences between the changes in the sub-humid regions among the models, and the humid regions are taken over by the sub-humid regions correspondingly. The spatial pattern of arid/humid zones over Asia based on simulated AI by separate models shows considerable similarities, although there are some differences in the details (Figs. S5, S6, S7, S8).

\section{Discussion}

This study used an aridity index to classify arid/humid climate regions over Asia and investigated changes in arid/humid patterns under future warming scenarios. Our results indicated a significant contraction in the humid region and an expansion in the arid region and the arid/humid transition zone under the scenario of national-committed emission reductions under the Paris Agreement. We quantified the change in the regional arid/humid pattern based on the self-determined emission reduction commitments, which are the current national mitigation commitments negotiated by governments. These results are more practical than those in previous studies based on RCP or $2.0^{\circ} \mathrm{C} / 1.5^{\circ} \mathrm{C}$ scenarios. Our results showed an arid trend in Asia in a warmer future. Upon examining the arid/humid region switch, previous studies pointed out that the boundaries of the East Asian climate transition zone would expand in both directions (Wang et al., 2017). The subtropical humid region in Southeast China showed a contraction, and the semi-arid and sub-humid regions in northern China showed a southeast expansion by the end of this century (Chan and Wu 2015; Li and Ma 2013; Huang et al. 2017). The trends they gave are similar to the trends in this study, but the values are slightly different. The possible reasons for the differences include (1) different regions of analysis (the East Asia for Wang et al. (2017), the China for Li and Ma (2013), the Asia in this study, and the larger regions for Chan and Wu (2015) and Huang et al. (2017)), and (2) different emission scenarios (the $2{ }^{\circ} \mathrm{C}$ warming scenario for Huang et al. (2017), the RCP 4.5 and 8.5 for Wang et al. (2017), the historical scenario for Chan and Wu (2015), and the national-committed emission scenarios in this study). The differences in emission scenarios are potentially more important. In this study, several new emission scenarios were updated based on 192 countries' INDC data, and then the characteristics of the arid/humid patterns under the new emission scenarios were re-estimated. We also evaluated how the areas of arid/humid climate regions change with continuous global warming (from current level to $>4{ }^{\circ} \mathrm{C}$ ). Our results provide useful information for policy design for climate change mitigation and adaptation.

Changes in arid/humid patterns are caused by multiple factors. Some scholars regard decreasing precipitation as the main reason for increased drought in many tropical and subtropical regions, along with changing atmospheric circulation and sea surface temperature (Dai 2012, Fu et al. 2015). In addition, temperature change may play an important role in shifting climatic regimes with continuous global warming (Feng et al. 2014), which leads to increasing deficits in water vapour pressure, increasing evaporation, and decreasing soil moisture. Our results show the amount of change in PET (a temperature-affected variable) is generally higher than that for precipitation in most regions over Asia, which indicates that the increase in atmospheric water demand with climate warming exceeds the increase in precipitation, and therefore affecting the arid/humid pattern. This finding is essentially consistent with those of studies based on the Palmer Drought Severity Index (PDSI) (Wang and Chen 2014). In addition, the arid/humid variations are generally affected by other factors, such as southeast and southwest monsoons, plateau monsoon in the Tibetan Plateau, westerly circulation, and West Pacific subtropical high (Liu et al. 2018; Yang et al. 2003). Therefore, the changes in arid/humid patterns are the results of complex effects of various factors.

\section{Conclusions}

Based on a combination of climate observational data and simulated data based on CMIP5 GCMs, we simulated PET by applying the revised Penman-Monteith model to calculate the AI over Asia. Projected arid/ humid patterns corresponding to different levels of climate warming were then investigated. We founded that the amount of change in PET is generally higher than that for precipitation, which determine decreasing $\mathrm{AI}$ in most regions. As the result, the humid region will contract significantly, whereas the semi-arid, and arid regions will expand. If global warming is limited to $2.0^{\circ} \mathrm{C}$ or $1.5^{\circ} \mathrm{C}$ instead of the INDC-pledge scenario, a remarkable reduction of more than half in the switch between the arid/humid regions is expected. Moreover, the humid/arid areas are likely to contract/expand greatly with continuous global warming. Mild changes in the boundary between different types of arid/humid climatic zones in the future can be distinguished from those in the present period. The simulated spatial patterns of arid/humid zones over Asia from multiple models have strong similarities but show some differences in detail. 


\section{Supplementary information}

Supplementary information accompanies this paper at https://doi.org/10. 1186/s40645-020-00325-3.

Additional file 1. Placed at the bottom of the last page due to too much text.

\section{Abbreviations}

Al: Aridity index; AR5: The Fifth Assessment Report; CMIP5: The Fifth Coupled Climate Model Intercomparison Project; CRU: Climate Research Unit; AR5: The Fifth Assessment Report; GCM: Global climate model; INDC: Intended Nationally Determined Contributions; IPCC: Intergovernmental Panel on Climate Change; P: Precipitation; PET: Potential evapotranspiration; RCP: Representative Concentration Pathway; UNFCCC: United Nations Framework Convention on Climate Change

\section{Acknowledgements}

We would like to thank three anonymous reviewers for their helpful comments. This work was supported by the National Key Research and Development Program of China (2019YFC0507805, 2016YFA0602704), the Strategic Leading Science and Technology Program of the Chinese Academy of Sciences (XDA20020202), and the National Natural Science Foundation of China (41771050).

\section{Authors' contributions}

writing —original draft preparation, J. Zhang; writing —extensively revised writing, F. Wang. All authors read and approved the final manuscript.

\section{Funding}

This work was supported by the National Key Research and Development Program of China (2019YFC0507805, 2016YFA0602704), the Strategic Leading Science and Technology Program of the Chinese Academy of Sciences (XDA20020202), and the National Natural Science Foundation of China (41771050).

\section{Availability of data and materials}

The CMIP5 dataset is available in https://esgf-node.Inl.gov/projects/esgf-IInl/. The CRU dataset is available in http://www.cru.uea.ac.uk/data.

\section{Competing interests}

The authors declare that they have no competing interests.

\section{Author details}

${ }^{1}$ Key Laboratory of Land Surface Pattern and Simulation, Institute of Geographic Sciences and Natural Resources Research, Chinese Academy of Sciences, Beijing 100101, China. ${ }^{2}$ College of Resources and Environment, University of Chinese Academy of Sciences, Beijing 100049, China.

Received: 25 September 2019 Accepted: 14 February 2020

Published online: 02 March 2020

\section{References}

Alessandri A, De Felice M, Zeng N, Mariotti A, Pan Y, Cherchi A, Lee J-Y, Wang B, Ha K-J, Ruti P, Artale V (2014) Robust assessment of the expansion and retreat of Mediterranean climate in the 21st century. Sci Rep 4:7211. https:// doi.org/10.1038/srep07211

Allan RP (2012) Regime dependent changes in global precipitation. Climate Dynamics 39(3):827-840. https://doi.org/10.1007/s00382-011-1134-x

Allen MR, Ingram WJ (2002) Constraints on future changes in climate and the hydrologic cycle. Nature 419:224. https://doi.org/10.1038/nature01092

Budyko (1974) Climate and life. Academic Press, New York

CAT. (2017). "Addressing global warming." https://climateactiontracker.org/global/ temperatures/. addressed on November 6, 2019

Chan D, Qigang W (2015) Significant anthropogenic-induced changes of climate classes since 1950. Sci Rep 5:13487. https://doi.org/10.1038/srep13487

Cook Bl, Smerdon JE, Seager R, Coats S (2014) Global warming and 21st century drying. Clim Dyn 43(9):2607-2627. https://doi.org/10.1007/s00382-014-2075-y

Dai A (2012) Increasing drought under global warming in observations and models. Nat Clim Chang 3:52. https://doi.org/10.1038/nclimate1633

Durman CF, Gregory JM, Hassell DC, Jones RG, Murphy JM (2001) A comparison of extreme European daily precipitation simulated by a global and a regional climate model for present and future climates. Q J R Meteorol Soc 127(573): 1005-1015. https://doi.org/10.1002/qj.49712757316

Feng S, Hu Q, Huang W, Ho C-H, Li R, Tang Z (2014) Projected climate regime shift under future global warming from multi-model, multi-scenario CMIP5 simulations. Global Planetary Change 112:41-52. https://doi.org/10.1016/j. gloplacha.2013.11.002

Fu Q, Feng S (2014) Responses of terrestrial aridity to global warming. J Geophys Res Atmospheres 119(13):7863-7875. https://doi.org/10.1002/2014JD021608

Fu YH, Zhao H, Piao S, Peaucelle M, Peng S, Zhou G, Ciais P, Huang M, Menzel A, Peñuelas J, Yang S, Vitasse Y, Zeng Z, Janssens IA (2015) Declining global warming effects on the phenology of spring leaf unfolding. Nature 526:104. https://doi.org/10.1038/nature15402

Gao X, Giorgi F (2008) Increased aridity in the Mediterranean region under greenhouse gas forcing estimated from high resolution simulations with a regional climate model. Global Planetary Change 62(3):195-209. https://doi. org/10.1016/j.gloplacha.2008.02.002

Greve P, Seneviratne SI (2015) Assessment of future changes in water availability and aridity. Geophys Res Lett 42(13):5493-5499. https://doi.org/10.1002/ 2015GL064127

Hanf F, Zittel J, Spangehl T, Cubasch U (2012) Shifts of climate zones in multimodel climate change experiments using the Köppen climate classification. Meteorol Z 21:111-123. https://doi.org/10.1127/0941-2948/2012/0344

Harris I, Jones PD, Osborn TJ, Lister DH (2014) Updated high-resolution grids of monthly climatic observations - the CRU TS3.10 dataset. Int J Climatol 34(3): 623-642. https://doi.org/10.1002/joc.3711

Held IM, Soden BJ (2006) Robust responses of the hydrological cycle to global warming. J Clim 19(21):5686-5699. https://doi.org/10.1175/JCLI3990.1

Hu K, Huang G, Xie SP (2019) Assessing the internal variability in multi-decadal trends of summer surface air temperature over East Asia with a large ensemble of GCM simulations. Climate Dynamics 52:6229. https://doi.org/10. 1007/s00382-018-4503-X

Huang J, Ma J, Guan X, Li Y, He Y (2019) Progress in semi-arid climate change studies in China. Adv Atmos Sci 36(9):922-937. https://doi.org/10.1007/ s00376-018-8200-9

Huang J, Yu H, Dai A, Wei Y, Kang L (2017) Drylands face potential threat under $2{ }^{\circ} \mathrm{C}$ global warming target. Nat Clim Chang 7:417. https://doi.org/10.1038/ nclimate3275

IPCC (2014) Climate change 2014: synthesis report. Contribution of working groups I, II and III to the Fifth Assessment Report of the Intergovernmental Panel on Climate Change. Cambridge University Press, Cambridge, UK, and New York, NY, USA

IPCC (2018) Global warming of $1.5^{\circ} \mathrm{C}$. Cambridge University Press, Cambridge, UK, and New York, NY, USA

Jones B, O'Neill BC (2016) Spatially explicit global population scenarios consistent with the shared socioeconomic pathways. Environ Res Lett 11(8):084003

Li MX, Ma ZG (2013) Soil moisture-based study of the variability of dry-wet climate and climate zones in China. Chin Sci Bull 58(4):531-544. https://doi. org/10.1007/s11434-012-5428-0

Liu J, Xu H, Deng J (2018) Projections of East Asian summer monsoon change at global warming of 1.5 and $2^{\circ} \mathrm{C}$. Earth Syst Dynamics 9(2):427-439. https://doi. org/10.5194/esd-9-427-2018

Ma D, Deng H, Yin Y, Wu S, Zheng D (2019) Sensitivity of arid/humid patterns in China to future climate change under a high-emissions scenario. J Geogr Sci 29(1):29-48. https://doi.org/10.1007/s11442-019-1582-5

McEvoy DJ, Huntington JL, Mejia JF, Hobbins MT (2016) Improved seasonal drought forecasts using reference evapotranspiration anomalies. Geophys Res Lett 43(1):377-385. https://doi.org/10.1002/2015GL067009

Middleton N, Thomas D (1997) World atlas of desertification (2nd Edn). UNEP, London, 182p

Pierce DW, Barnett TP, Santer BD, Gleckler PJ (2009) Selecting global climate models for regional climate change studies. Proc Natl Acad Sci 106(21):8441. https://doi.org/10.1073/pnas.0900094106

Reichler T, Kim J (2008) How well do coupled models simulate today's climate? Bull Am Meteorol Soc 89(3):303-312. https://doi.org/10.1175/BAMS-89-3-303

Robert V, Andreas G, Stefan S, Erik K, Annemiek S, Paul W, Thomas M, Oskar L, Grigory N, Claas T, Daniela J (2014) The European climate under a $2^{\circ} \mathrm{C}$ global warming. Environ Res Lett 9(3):034006

Rogelj J, den Elzen M, Höhne N, Fransen T, Fekete H, Winkler H, Schaeffer R, Sha F, Riahi K, Meinshausen M (2016) Paris Agreement climate proposals need a boost to keep warming well below $2{ }^{\circ} \mathrm{C}$. Nature 534:631. https://doi.org/10. 1038/nature18307 
Rohli RV, Andrew Joyner T, Reynolds SJ, Shaw C, Vázquez JR (2015) Globally extended Köppen-Geiger climate classification and temporal shifts in terrestrial climatic types. Phys Geogr 36(2):142-157. https://doi.org/10.1080/ 02723646.2015 .1016382

Schleussner C-F, Lissner TK, Fischer EM, Wohland J, Perrette M, Golly A, Rogelj J, Childers K, Schewe J, Frieler K, Mengel M, Hare W, Schaeffer M (2016) Differential climate impacts for policy-relevant limits to global warming: the case of 1.5 \&deg;C and 2 \&deg;C. Earth Syst Dynamics 7(2):327-351. https:// doi.org/10.5194/esd-7-327-2016

Sherwood S, Qiang F (2014) A drier future? Science (New York, N.Y.) 343:737-739. https://doi.org/10.1126/science.1247620

Sylla MB, Elguindi N, Giorgi F, Wisser D (2016) Projected robust shift of climate zones over West Africa in response to anthropogenic climate change for the late 21st century. Clim Chang 134(1):241-253. https://doi.org/10.1007/s10584015-1522-z

Taylor KE, Stouffer RJ, Meehl GA (2011) An overview of CMIP5 and the experiment design. Bull Am Meteorol Soc 93(4):485-498. https://doi.org/10 1175/BAMS-D-11-00094.1

Trenberth KE, Dai A, van der Schrier G, Jones PD, Barichivich J, Briffa KR, Sheffield J (2013) Global warming and changes in drought. Nat Clim Chang 4:17. https://doi.org/10.1038/nclimate2067

UNFCCC. (2015a). Adoption of the Paris Agreement: proposal by the president. Edited by FCCC/CP/2015/L.9/rev.1. Geneva

UNFCCC. (2015b). Synthesis report on the aggregate effect of the intended nationally determined contributions. Edited by FCCC/CP/2015/7. Paris

UNFCCC. (2019). National Inventory Submissions

van Vuuren DP, Edmonds J, Kainuma M, Riahi K, Thomson A, Hibbard K, Hurtt GC, Kram T, Krey V, Lamarque JF, Masui T, Meinshausen M, Nakicenovic N, Smith SJ, Rose SK (2011) The representative concentration pathways: an overview. Clim Chang 109(1-2):5-31. https://doi.org/10.1007/s10584-011-0148-z

Wang F, Tokarska KB, Zhang J, Ge Q, Hao Z, Zhang X, Maowei W (2018) Climate warming in response to emission reductions consistent with the Paris Agreement. Adv Meteorol 2018:1-9. https://doi.org/10.1155/2018/2487962

Wang L, Chen W (2014) A CMIP5 multimodel projection of future temperature, precipitation, and climatological drought in China. Int J Climatology 34. https://doi.org/10.1002/joc.3822

Wang L, Chen W, Huang G, Zeng G (2017) Changes of the transitional climate zone in East Asia: past and future. Clim Dyn 49(4):1463-1477. https://doi.org/ 10.1007/s00382-016-3400-4

Yang J, Ding Y, Chen R, Liu L (2003) The fluctuation of dry and wet climate boundary and its causal analyses in China. Acta Meteorologica Sinica 61(3): 364-374. https://doi.org/10.11676/qxxb2003.035

Yang Q, Li MX, Zheng ZY, Ma ZG (2017) Regional applicability of seven meteorological drought indices in China. Science China Earth Sciences 60(4): 745-760. https://doi.org/10.1007/s11430-016-5133-5

Yin Y, Ma D, Wu S, Pan T (2015) Projections of aridity and its regional variability over China in the mid-21st century. Int J Climatol 35(14):4387-4398. https:// doi.org/10.1002/joc.4295

Zhang J, Wang F (2019) Extreme precipitation in China in response to emission reductions under the Paris Agreement. Water 11(6). https://doi.org/10.3390/ w11061167

\section{Publisher's Note}

Springer Nature remains neutral with regard to jurisdictional claims in published maps and institutional affiliations.

\section{Submit your manuscript to a SpringerOpen ${ }^{\circ}$ journal and benefit from:}

- Convenient online submission

- Rigorous peer review

- Open access: articles freely available online

- High visibility within the field

- Retaining the copyright to your article

Submit your next manuscript at $\boldsymbol{\nabla}$ springeropen.com 